\title{
Systemic Integration of Occupational Health and Safety within Business Management
}

\author{
Ana PAUN ${ }^{\star}$, Roland MORARU $^{\star \star}$, Claudia ISAC ${ }^{\star \star \star}$
}

\begin{tabular}{l}
\hline \multicolumn{1}{c}{ A R T I C L E I N F O } \\
\hline Article history: \\
Accepted April 2019 \\
Available online April 2019 \\
\hline JEL Classification \\
D24, D29 \\
Keywords: \\
Occupational health and safety, \\
Business management, Total \\
Quality Management, Lean \\
Production, Six Sigma, Balanced \\
Scorecard, Risks management
\end{tabular}

1. Introduction

Lately, the vastness of the major objectives of the large companies has increased considerably, from surveying limited targets, such as the increase of profits and the initiation of investment projects, to assuming ampler roles that concern business sustainability and durable development. Irrespective of the objective to be surveyed, a good performance in the field of the occupational health and safety means a better business, a performing management, sustainability and competitiveness. Companies should integrate OHS within business management and increase the degree of awareness of the main decisional factors in connection with the importance of this objective.

Due to the fact that, at present, corporations apply increasingly elevated standards of corporate governing, a larger number of companies become aware of the important advantages that may result from integrating OHS within business management: improvement of the image and reputation of the company, continual improvement of labor conditions, of labor safety, meeting of the commitments that regard companies' corporate social responsibility, maintaining and improving investors' confidence.

\section{Literature review}

The implementation of the systems of OHS management has had as a main objective the improvement of occupational health and safety in accordance with the policies and strategies settled at a European and international level. Relying on such strategies, the systems of OHS management have developed and have been implemented by a large number of companies worldwide. Despite all these intense preoccupations, it is nonetheless evident that there is no consensus as far as the objective of OHS management is concerned. This aspect was shown by Nielsen (2000), who asserts that: "the systems of OHS management surely do not represent a well-defined group of management systems. It is sure that there is no concise delineation among OHS activities, OHS management and OHS system of management".

In accordance with the definition set forth by I.M.O. (International Migration Organization), a system of OHS management represents "a group of elements that are interrelated and interact with a view to settle and carry out the policies and objectives that regard occupational health and safety". These elements may include: OHS policy, planning, organizational structure and responsibilities, communication and training, risk management, monitoring, preventive and corrective actions. Continual improvement represents one of the

\begin{abstract}
A B S T R A C T (Occupational Health and Safety) as part and parcel of business general management.
Considering the fact that such an integration allows the increase of the business sustainability, we made an inventory of the most relevant opinions found in specialized literature in connection with the concepts and models of OHS management systems; we transition from the traditional management to the OHS systemic management with a view organizational performance. The second part of the paper displays the systems and the degrees of integrating OHS within business management through: the management and
promotion of occupational health and safety, an integrated management of health and the systems of integrating occupational health and safety within quality programs through the (BSC). Beyond the limitations of a theoretical study, we consider that the specific aspects of specialists owing to the increased interest of the organizations for er are useful for the support in implementing a performing management.
\end{abstract} . 
most important elements of the successful functioning of the system, which is closely connected with the evaluation of performance and relies upon the well-known PDCA model (Plan - Do - Check - Act), namely the Deming cycle (Deming, 1982).

In accordance to the well-known international standard OHSAS 18001, a system of OHS management is defined as a part of the management system of an organization, employed with a view to developing and implementing the organization's OHS policy and to administer occupational health and safety risks. In accordance with this standard, the OHS system is a group of interdependent elements used for defining the policy and the objectives; in order to attain the objectives already settled, the system includes an organizational structure, planning activities, responsibilities, practices, processes and resources.

\section{OHS management}

As far as the analysis and/ or description of OHS management as a component of the business management of an organization is concerned, ASET model (Shaw and Blewett, 2000) deserves to be emphasized; the model, in accordance with the figure below, has four basic elements, which are: the atmosphere that shows the interdependence among the organization's culture, values and principles, the systems that include rules, procedures and standards, especially those that interact with OHS, the display that shows the connections between the organizational behavior and the business environment and the objectives of OHS management that include specific measurable targets, such as zero occupational accidents, zero occupational diseases, etc.

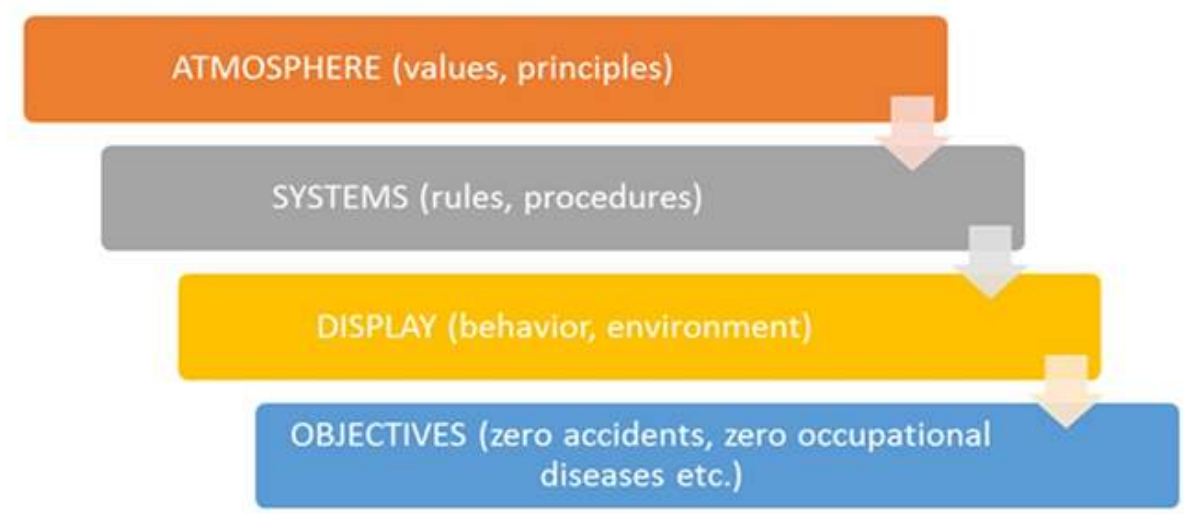

Fig. 1. Structure of ASET model

Source: Adapted after: Moraru, R.,I., Băbut,, B.,G., Băbuț, C.,M., - Integrarea SSM în managementul afacerilor: o meta-analiză, Revista "Calitatea - acces la succes", vol. 12, no. 125/2011, pp. 65-79

The model shows that each organization should be approached in accordance with its own context characterized by its own specific internal structure, organizational culture and capacity of adapting to the business environment. At its turn, safety culture and OHS management depend on the global governance of the organization, including factors such as Corporative Social Responsibility, Social Responsibility and Corporate Sustainability.

All these factors show the complexity of the global governance of organizations, which requires an organizational management where OHS management represents an important component. It is clear that such a symbiosis can be created through specific instruments and through neat development and implementation stages:

$>$ The ad hoc stage, according to which organizations own a low level of expertise in OHS management and solve the problems as they come out;

$>$ The systematic stage, in accordance to which organizations carry out, at certain moments, internal evaluations that concern the increase of safety, prefiguring their actions, prioritizing the issues and implementing the measures able to diminish the risks; they may also choose to appeal to external expertise as a means of evaluating management efficiency;

$>$ The systemic stage, according to which organizations implement and maintain a system of OHS management through organizing specific activities and initiating new activities;

$>$ The proactive stage, in accordance to which organizations introduce OHS management within the other management systems and/ or economic processes, stressing continual improvement, intensifying the efforts during the stage of designing the products, processes, jobs and labor organizing, and emphasizing collective learning.

The evolution of the systemic approaches that concern OHS management has become necessary and is a direct consequence of the legislative reforms in the field, mainly in the industrially developed countries. In accordance, OHS management has evolved from a mainly prescriptive style towards a flexible style, relying 
on "settling objectives" (Frick and Wren, 2000; Bluff, 2003) and operational feedback that has forged a general framework of OHS management.

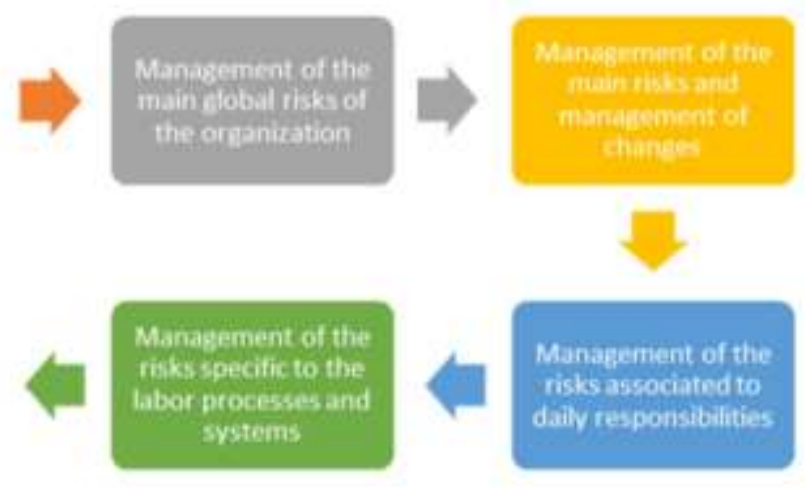

Fig. 2. Multi - faceted approach of risk management

Source: Adapted after Moraru, R.,I., Băbuț, B.,G., Băbuț, C.,M., - Integrarea SSM în managementul afacerilor: o meta-analiză, Revista “Calitatea - acces la succes", vol. 12, no. 125/2011, pp. 65-79

In comparison with OHS traditional programs that are more reactive, at present a multi-faceted approach of risk management is developed, which relies on a systematic management and displays a proactive, participative character that is better integrated within the activities of the organization. In fact, risk management is operational owing to the categories of risks involved, namely: global risks connected with the general activity of the organization and starting from the performance and financial balance of the company, market risks, etc.; risks determined by the management of the internal and external changes, such as: environment risks, global financial crisis risks, energy crisis risks; risks specific to labor processes and systems associated to operational risks, technological risks, whose diminishing increases the efficiency of the activities and of OHS management; risks associated to daily responsibilities, mainly diminished through operational procedures implemented efficiently at each job.

With a view to characterize the two types of management, namely the traditional one and the systematic one, one should rely on motivation, responsibility, evaluation, objectives and effects resulted, elements that are displayed in the figure below:
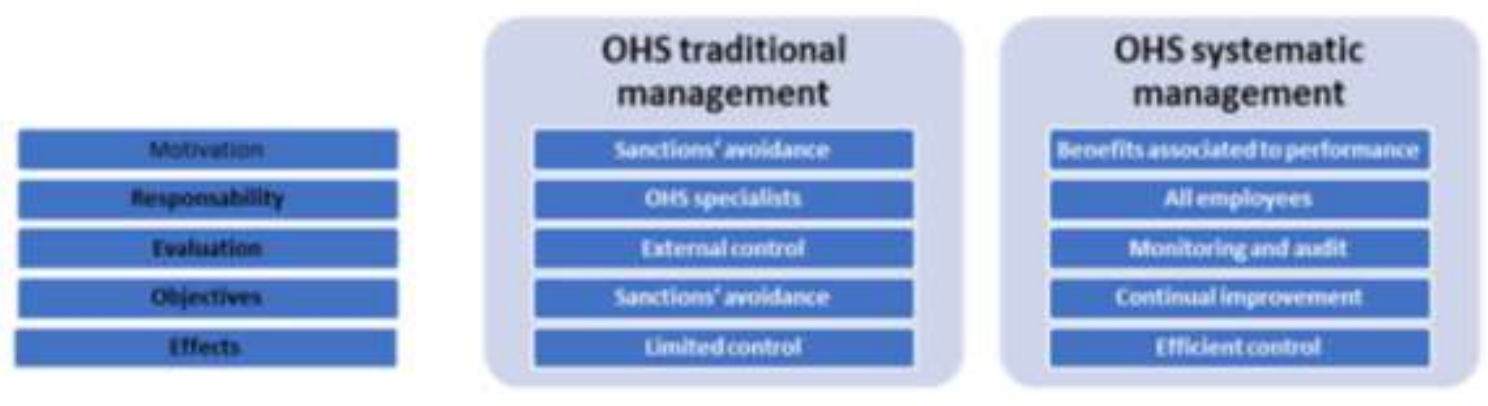

Fig. 3. Comparative elements between the "traditional" and the "systematic" OHS management

Specialized literature shows differences between the systematic OHS management, considered as a "limited number of principles mandated for the OHS systematic management, which may be applied for all types of employers, including small and medium range companies" and the "much more complex and highly specific systems of OHS management" (Frick, 2004). Even the European Agency for Safety and Health at Work, in its report concerning the "Use of the Management Systems of Occupational Health and Safety in the States Members of the European Union: Experience at the Level of the Companies". (EASHW, 2002) shows that "the ideal system of OHS management" consists in a large number of process and content variables that regard the system's inputs, specific forms, system's implementation, its effects and improvement (Figure 4.). 


\begin{tabular}{|c|c|c|c|c|c|c|c|}
\hline$\frac{\text { Initiation - }}{\text { Input }}$ & $\begin{array}{l}\text { Commitment and } \\
\text { resources }\end{array}$ & $\begin{array}{l}\text { Legislative and } \\
\text { systemic } \\
\text { congruency }\end{array}$ & $\begin{array}{l}\text { Responsibility and } \\
\text { authority }\end{array}$ & $\begin{array}{l}\text { Employees } \\
\text { participation }\end{array}$ & & & \\
\hline$\frac{\text { Formulation }}{\text { Process }}$ & SSM policy & $\begin{array}{l}\text { SSM objectives } \\
\text { and targets to be } \\
\text { attained }\end{array}$ & $\begin{array}{c}\text { Measuring } \\
\text { performance }\end{array}$ & $\begin{array}{c}\text { System } \\
\text { planning and } \\
\text { development }\end{array}$ & $\begin{array}{c}\text { Initial } \\
\text { evaluation/ } \\
\text { Risk evaluation }\end{array}$ & & \\
\hline$\frac{\text { Implementation - }}{\text { Processes }}$ & Training system & $\begin{array}{c}\text { Technical } \\
\text { experience and } \\
\text { employees' skills }\end{array}$ & $\begin{array}{l}\text { Dangers control } \\
\text { system }\end{array}$ & $\begin{array}{c}\text { Process } \\
\text { designing }\end{array}$ & $\begin{array}{l}\text { Response } \\
\text { capacity in } \\
\text { emergency } \\
\text { situations }\end{array}$ & $\begin{array}{l}\text { System of } \\
\text { preventive } \\
\text { and } \\
\text { corrective } \\
\text { actions }\end{array}$ & $\begin{array}{l}\text { Documenting } \\
\text { and } \\
\text { contracting }\end{array}$ \\
\hline$\frac{\text { Effects }}{\text { Results }}$ & $\begin{array}{l}\text { Objectives and } \\
\text { goals }\end{array}$ & $\begin{array}{l}\text { Accident and } \\
\text { illnesses indices }\end{array}$ & Employees health & $\begin{array}{l}\text { Changing } \\
\text { efficiency }\end{array}$ & $\begin{array}{l}\text { Organization's } \\
\text { global } \\
\text { performance }\end{array}$ & & \\
\hline$\frac{\text { Evaluation and }}{\frac{\text { integration }}{\text { Feed-back }}}$ & $\begin{array}{l}\text { Communication } \\
\text { and improvement }\end{array}$ & $\begin{array}{l}\text { Management } \\
\text { system/ } \\
\text { documents }\end{array}$ & $\begin{array}{c}\text { Self-evaluation } \\
\text { and audit, revising } \\
\text { management } \\
\text { processes }\end{array}$ & $\begin{array}{l}\text { Analyzing } \\
\text { incidents and } \\
\text { the tree of } \\
\text { causes }\end{array}$ & $\begin{array}{l}\text { Health } \\
\text { monitoring } \\
\text { program }\end{array}$ & & \\
\hline
\end{tabular}

Figure 4. Basic elements of an ideal system of OHS management

Adapted after: (EASHW, 2002)

The integration of the occupational health and safety processes within business management displays as a major strength the getting of supplemental values that materialize in: matching the objectives of occupational health and safety with economic objectives, settling a logic framework for substantiating the programs of occupational health and safety, settling a portfolio of more precise policies, procedures and objectives that are more easily transmitted to the interested factors, increased applicability and degree of inclusion for the possible differences of organizational culture, settling a methodology of continual improvement, providing representative indices for quantifying performance.

\section{Systems and levels of integrating OHS within business management}

Irrespective of the approaches displayed by specialized literature, the positive effects of OHS implementation concern: the decrease of accident occurrence indices and the increase of productivity, the diminished compensations given to employees, the improvement of the health and safety organizational environment, the improvement of the attitude of the employees that regard the labor physical and psychosocial environment, the active involvement of the employees in activities that relate to labor health and safety. In order to develop an efficient OHS organizational management and, implicitly, an efficient business management, the following system and levels of integration should be observed:

\section{A. The management and promotion of occupational health and safety}

The promotion of occupational health and safety concerns the coordinated actions of all the individuals that are part of the company and corporation - employees, employers, citizens, and services with a view to creating a pleasant and healthy labor environment, which should be a balanced milieu, in accordance with the harmonious development of the economic unit, both technically and economically. With this in view, companies target to better organize labor so that to be able to facilitate the active involvement of the employees in OHS activities, a fact that has as a positive consequence the personal development of each employee. The main fields for promoting occupational health and safety include:

$>$ The leadership component within the context of organizational culture;

$>$ The activities of corporate social responsibility;

$>$ The professional increase of human resources;

$>$ The maintaining of a balance between the private and the professional life;

$>$ The management of stress and psycho-social risks; maintaining and improvement of mental health;

$>$ The life style of human resources;

$>$ Diet and welfare.

These seven fields of activity are not restrictive and the adoption of planning or behavioral change models that regard occupational health and safety involve their interdependence and advanced cooperation of all those implied, for instance: primary medicine and public health, human resources departments and research units or academic education (Vries H.et al, 2018).

\section{B. The integrated health management}

At present, for a durable development, organizations require qualified, motivated and efficient workers, able and available to contribute actively to technical and organizational innovations, as well as clients and consumers that are increasingly interested in healthy products and services; meanwhile, health 
has become a (potential) business value of strategic importance. The concept of Integral Health Management (IHM) (Zwetsloot and van Scheppingen, 2007) is implemented when interacting with all the interested parts and provides an integrated OHS approach, owing to the fact that a lot of organizations face a high level of health issues with both negative effects upon labor productivity and suffering for employees.

In accordance with IHM, health represents an essential factor of the organization's strategy and the seven main IHM development coordinates target (Zwetsloot and Pot, 2006):

$>$ Heath as a strategy and priority component of the company;

$>$ Carrying out "healthy" primary processes;

$>$ Work environment health and safety;

$>$ Encouraging a social work environment among the employees;

$>$ Tonus and health for the employees;

$>$ Healthy relations within the organization and the local community;

$>$ Activities' result should be materialized in healthy services and products.

Zwetsloot and Pot consider that, owing to this model, the following may be reached: lower costs of medical care, decrease of the temporary or permanent labor incapacity of the employees corroborated with an increased productivity and resistance capacity of the organization and its employees. All these are going to result in direct economic benefits for the company.

\section{Integration of occupational health and safety in quality programs}

Product quality and cost decrease or their controlling are increasingly determined by pressure from consumers, on the one hand, and from the market, namely from the organization's competitors, on the other hand. With a view to counteract this tendency and give the organizations the possibility to face changes, there are several strategies that allow the efficient implementation of management strategies: Total Quality Management, Lean Production, Business Excellence Models (such as EFQM Model of the European Foundation for Quality Management or the American Malcom Baldrige Criteria for Performance Excellence, Six Sigma and Balanced Scorecard).

\section{C.1. Total Quality Management (TQM)}

TQM concept (Total Quality Management) is defined as a management strategy whose goal is the integration of quality within all the processes of the company. In accordance with the terminology, the entire appellation of the concept is the following one: "Total Quality Management" (according to ISO 8402:1994 the English version) or "management total de la qualité" - the French version). TQM is regarded by Wilkinson from the perspective of consumers as a "philosophy of business management that has as a goal the continual improvement of client satisfaction through the management of products and services quality implemented at the level of the whole company". In accordance with the American Society for Quality, "TQM is a management approach for long-term success through client satisfaction". Meanwhile, in accordance with ISO standards, Total Quality Management (TQM) is the manner of administering an organization, rallying on quality and the involvement of all its members and targeting both a long-term success through client satisfaction and benefits for all the members of the company and for society. The systemic vision of Hellsten and Klefsjö shows that TQM is "a continual development management system consisting in values, methodologies and instruments, whose goal is the increase of the satisfaction of external and internal clients relying on a decreased amount of resources"

Osborne and Zairi propose an interesting approach and define TQM from an operational perspective as a "process that allows a business to continually improve its capacity of responding demands and exceeding the needs and expectancies of the interested factors through focusing its economic processes upon a series of welldefined objectives, policies and strategies and through controlling them while implementing measurements and systematic revisions, within an organization and culture that provide a positive leadership, which has in view the accomplishing of its mission through the implication, support, participation and acknowledgement of the achievements and efforts of the employees" (Osborne and Zairi, 1997).

Irrespective of these approaches, an integrative vision upon TQM principles asserts itself when attempting at carrying out the objectives of occupational health and safety. A study including 24 companies, carried out by the European Centre for Total Quality Management, has shown the extent to which OHS management incorporated TQM principles (Osborne and Zairi, 1997) as well as the manner the specific principles were applied to the main OHS activities. In accordance, more specifically, the main elements of TQM employed by OHS regard the following: the executive identity level and the level of understanding OHS; the extent to which the interested factors value welfare and safety; the clients' demands that require the company to own practices, standards and values that are similar with theirs; the definition of a top business strategy through a valuable management; the manner the part played by occupational health and safety is perceived within organizations.

\section{C.2. "Lean production" concept}

"Lean" type production also regards the manner the activity of an organization is administered. In accordance with this concept, an organization's allocating an amount of money for objectives different than those which create value is considered a loss. Under such circumstances, the target is the value of the product and the final consumer. A continual process of eliminating losses occurs during each stage the product passes 
through up to the final consumer. "Lean" type production largely derives from Toyota Production System, which possesses its own "lean" production system, called Toyota Production System (TPS). The basic principle of "lean production" refers to minimizing or eliminating losses, while identifying seven specific forms of loss: correction, overproduction, movement, stuff movement, waiting periods, inventory and process. Part and parcel of the lean production model is the management of the life cycle of the product (PLM). A definition of PLM can be found in WordIQ Dictionary: "The management of the product life cycle or PLM represents the process of administering the whole life cycle of the product, from the concept and designing stage, to product's analysis, planning, visualizing and marketing it and to the moment when the user withdraws the product which is no more used (waste management and recycling)".

From the point of view of business management, Sergio Terzi defines PLM as "a model of business focused on the life cycle of the product, supported by information and communication technology where the data concerning the product are divided among the actors, processes and organizations belonging to the various stages of the life cycle of the product, with a view to achieving the desired performance and sustainability for the product and the associated services".

As far as the domain of occupational health and safety is concerned, the implementation of the "lean" concept has determined significant issues (Main ş.a., 2008, p. 39), due to the fact that "lean production focuses on minimizing a system's losses while safety focuses on minimizing a system's risks. Optimizing the one or the other may determine a sub-optimal solution for the global system - minimal loss but increased risk or minimal risk bur increased losses". Nonetheless, labor health and safety as well as the "lean" concept are not in a conflict of objectives; they even own a mutual objective, namely maximizing production through minimal risks and losses. In accordance, one may regard accidents as losses which should not occur. Consequently, both OHS management and the management of "lean" production should face the same challenge: the limitative character of resources, instability and capacity to predict and adapt to unpredictable events.

\section{C.3. Models of business excellence}

The models of business excellence show the manner an organization should act with a view to get the highest level of performance. The models of excellence most widely known are the following ones:

$>$ Australian Business Excellence Framework (ABEF) - Australia

$>$ Baldrige (MBNQA) - used in over 25 countries, including USA and NZ

$>$ Canadian Business Excellence Model - Canada

$>$ European Foundation for Quality Management (EFQM) - Europe

$>$ Japan Quality Award Model - Japan

$>$ Juran Quality Award Model - Romania

$>$ Deming Award - Japan

$>$ Singapore Quality Award Model - Singapore

With a view to developing and testing the self-evaluation criteria that regard occupational health and safety performance, Ketola and his team (2002) employed the principles of business excellence. The criteria of excellence in performance proved to be quite adequate for finding out the initial safety status of an organization and for proposing the first measures that might provide an improvement. The improvement has occurred even in the case of those categories with which the members of the project were not acquainted or in the case of those who had nothing in common with OHS. In fact, the specific features of OHS management are not characterized by the importance given to leadership or human resources; that is why both the strengths and the fields requiring improvement are to be observed in such cases. This model shows a pertinent enough image of the degree of performance of the organization's OHS and emphasizes the strengths, while increasing performance improvement. In conclusion, the implementation of the models of excellence allows o good foundation for systematizing the organizing of occupational health and safety in the case procedures are properly documented.

\section{C.4. Six Sigma}

Six Sigma relies on the statistic methods of improving products' quality. This term was used for the first time during the 1980s, within the engineering department of Motorola, with a view to reaching processes or products that were statistically infallible. The subsequent development of the concept is acknowledged by the International Standardization Organization (ISO), which, in 2011, elaborated standard ISO 13053:2011 that describes "a methodology for the methodology of business improvement known as Six Sigma. The methodology typically includes five stages: defining, measuring, analyzing, improving and control (DMAIC)". Nowadays, the organizations that integrate this concept create both perfect products and increasingly efficient administrative and production groups (Isaic-Maniu A., 2009). In accordance with Williamsen's theory (2006), the connection between Six Sigma and OHS management is carried out through six levels of control displayed in the following table: 
Table no. 1. Connection between Six Sigma and the level and content of OHS processes

Level of control

First level of control

Sigma

Second level of control

Sigma

Third level of control

Sigma

Fourth level of control

Sigma

Fifth and sixth levels of

control Sigma

\section{OHS matching}

Provides the conditions for a safe work place through observing imposed rules and training the employees

Monitoring and analyzing the concern for labor safety and reporting possible incidents

Regularly settling predictable objectives through distributing specific responsibilities to the employees

Actively involving the employees through increased monitoring the perception upon occupational safety and diagnosing specific elements

Developing a durable safety culture that may implicitly provide the taking of the most efficient decisions owing to three factors: the team of specialists dedicated to continual improvement, the active participation of all the employees and the use of permanent control instruments.

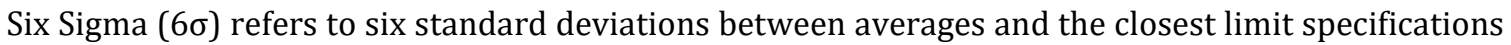
of all processes. With a view to observing the criteria imposed by Six Sigma, all processes have to be close to perfection, reaching $99.9997 \%$, that is, in the case of 1 million chances no more than 3.4 failures may come out. Under such circumstances, Six Sigma methodology might be used by OHS management in order to eliminate production existing errors and to reduce labor accidents. All these six levels may also be approached from the OHS perspective, each of them relying on the previous level until "Six Sigma" level is attained, namely zero accidents (Williamsen, 2006). As a conclusion, implementing Six Sigma represents a requirement for the domain of occupational health and safety and a condition for business sustainability.

\section{C.5. "Balanced Scorecard” system (BSC)}

Balanced Scorecard (BSC) was conceived during the 1990s by Robert S. Kaplan, Professor at Harvard University and by David P. Norton, management consultant, with a view to measuring the performance of organizations through financial metrics capable of quantifying companies' success (Kaplan, 2009). Due to the fact that most of the classic instruments emphasize financial results, this system attempts at improving and integrating intangible assets, such as OHS elements. BSC has in view the analysis of four categories of indices playing an important part in the process and upon which a "balanced scorecard" most frequently relies: indices specific for the financial field, indices regarding communication, indices belonging to the operational area as well as development and educational indices. The implementation of this method is further employed, by Mearns and Havold (2003, p. 415), within OHS, the representation indices being displayed in the next table:

Table no. 2. "Balanced scorecard" indices

Concerning occupational health and safety

\begin{tabular}{|c|c|}
\hline Specific domains & Representation indices \\
\hline \multirow{2}{*}{ Financial domain } & Expenditures associated with labor accidents \\
\hline & Expenditures concerning safety investments \\
\hline \multirow{2}{*}{$\begin{array}{l}\text { Communication } \\
\text { domain }\end{array}$} & Level of communication that regard OHS aspects \\
\hline & Degree of involvement and participation of the employees in specific activities \\
\hline \multirow{8}{*}{$\begin{array}{l}\text { OHS operative } \\
\text { domain }\end{array}$} & Degree of implementation of OHS policies \\
\hline & Level of structural organizing \\
\hline & Degree of controlling the efficiency of OHS activities \\
\hline & Degree of cooperation in organizing specific activities \\
\hline & Level of specialists' competence \\
\hline & $\begin{array}{l}\text { Demonstration of management team commitment and degree of employees' } \\
\text { implication in OHS }\end{array}$ \\
\hline & Occupational health and safety audit \\
\hline & Monitoring and promoting OHS \\
\hline \multirow[t]{5}{*}{ Educational domain } & Periodical evaluation of employees' knowledge concerning OHS policies \\
\hline & Managers' visits to operational areas and direct dialogue with the employees \\
\hline & $\begin{array}{l}\text { High number of employees waiting for the monthly meeting of the Committee for } \\
\text { Occupational Health and Safety }\end{array}$ \\
\hline & Efficient implementation of the plan for prevention and protection \\
\hline & Level of corrective and preventive actions concluded during the previous year \\
\hline
\end{tabular}

BSC is a flexible instrument that changes with the long term evolution of the organization; it is not an instrument that is going to determine short term favorable results. Taking into account the fact that OHS 
management is an important factor of organizations' sustainability, the advantages offered by BSC implementation are extremely convincing.

\section{Conclusions}

Correlating OHS with the integration system displayed has multiple advantages for organizations, for the integration of OHS management within business management and allows the implementation of occupational health and safety not only as a legal and social obligation, but as an essential factor that determines the increase of competitiveness, profitability, employees' motivation, prevention or minimal occurrence of accidents and illnesses.

As a conclusion, OHS represents an essential element of business efficiency owing to the fact that it improves brand image, maximizes employees' productivity, increases employees' loyalty for the company, maintains the competence and health of the employees, reduces costs and the periods when activity is interrupted and encourages employees to be active for a longer period of time. Consequently, integrating OHS within the global management and business of an organization determines safer and healthier work environments as well as a better general organizational performance, providing the increase of business sustainability.

\section{References}

1. Hellsten, U., Klefsjö, B. (2000), TQM as a management system consisting of values, techniques and tools. The TQM Magazine, 2000, vol. 12, iss. 4, 238-244

2. Herman, E. (2011a). The Impact Of The Industrial Sector On Romanian Employment, Journal of Knowledge Management, Economics and Information Technology, Volume I, Issue 6, October 2011

3. Isaic-Maniu A., Vodă V. (2009), Abordarea șase sigma, Editura Economică, București

4. Răscolean I, Dura C., Isac C., Economia și gestiunea întreprinderii: fundamente teoretice și studii de caz, Ed. Sitech, Craiova, 2014

5. Terzi, S. et al. (2010), Product lifecycle management -from its history to its new role. In: Int.J.Product Lifecycle Management, Vol. 4, No. 4, 360-389

6. Vries, H., Kremers S.P.J., Lippke S. (2018), Health Education and Health Promotion: Key Concepts and Exemplary Evidence to Support Them. In: Fisher E. et al. (eds) Principles and Concepts of Behavioral Medicine. Springer, New York, $N Y, 489-532$

7. Wreder, L. (2007), Successful Management Methodologies for Achieving Co-Worker Health in a Large Organization, Total Quality Management \& Business Excellence, vol. 18, issue 7, 823844, DOI: 10.1080/14783360701349948

8. Wilkinson, A., Marchington, M. \& Dale, B. (1994), Manufacturing More Effective TQM: Implications for the Management of Human Resources, Research and Practice in Human Resource Management2(1), pp. 69-88

9. Zwetsloot, G., Pot, F. (2004), The Business Value of Health Management, Journal of Business Ethics, December 2004, Volume 55, Issue 2, 115-124

10. ${ }^{* * *} A S Q$, Glossary-Entry:Total Quality Management

11. ${ }^{* * *}$ EU strategy 2007-2012 concerning occupational health and safety, national strategy in the field of occupational health and safety for the period 2017-2020

12. *** Ghid practic de managementul calității pentru firmele performante, Editura Niculescu SRL, București, 1999,115

13. *** http://www.managementulperformantei.ro

14. *** ISO 13053:2011- Quantitative methods for improving Six Sigma process

15. *** SR ISO 8402: 1995. Quality Management and Quality providing. Vocabulary

16. *** WordIQ.com (2010). Product Lifecycle Management - Definition 